\title{
Mudanças de Uso e Cobertura da Terra e Áreas Suscetíveis à Inundação - Estudo de Caso do Município de Duque de Caxias/RJ
}

\author{
Land Use and Land Cover Changes and Flooding Areas - \\ Case study of the County of Duque de Caxias/RJ
}

\author{
Luciana Viana Neves ${ }^{1} \varangle$ iD, Leandro Andrei Beser de Deus ${ }^{2} \varangle$, Antonio Carlos da Silva Oscar Júnior ${ }^{3} \bowtie$ \\ Manoel do Couto Fernandes $4 \square$
}

\author{
1 Universidade do Estado do Rio de Janeiro, ciana.vn@gmail.com, \\ https://orcid.org/0000-0003-2446-7548 \\ 2Universidade do Estado do Rio de Janeiro, leandrobeser@gmail.com \\ 2Universidade do Estado do Rio de Janeiro, thony.oscar@gmail.com \\ 2Universidade Federal do Rio de Janeiro, manoelcoutofernandes@gmail.com
}

Recebido (Received): 15/08/2018

Aceito (Accepted): 29/01/2019

Resumo: O número de eventos de desastres naturais tem aumentado ao longo do tempo no território brasileiro e no mundo inteiro. No contexto brasileiro, há expressiva ocorrência de eventos de natureza hidrológica a exemplo das inundações, deslizamentos e secas. O presente artigo relaciona as mudanças de uso e cobertura do solo no município de Duque de Caxias, rotineiramente afetado por eventos de inundação, entre 2007 e 2016 (período dentro da vigência do segundo plano diretor municipal), com o resultado do mapeamento das áreas suscetíveis à inundação, realizado pelo CPRM (2013). As mudanças foram inferidas através do modelo Land Change Modeler (LCM), e os insumos de entrada correspondem à mapas de uso e cobertura do solo classificados supervisionadamente com o uso do algoritmo CART, na plataforma Google Earth Engine, através de imagens Landsat 5, sensor TM, bandas 4 (infravermelho próximo), 3 (vermelho) e 2 (verde), e Landsat 8, sensor OLI, Bandas 5 (infravermelho próximo), 4 (vermelho) e 3 (verde), ambas com resolução de 30m x 30m. Analisou-se as classes "urbano", "vegetação densa", "vegetação rasteira" e "solo exposto". Busca-se com este trabalho identificar quais classes obtiveram maiores mudanças no período de análise, se estas tendem a ocorrer em áreas classificadas como alta suscetibilidade à inundação e a probabilidade de uma classe se tornar outra em 2026 (através da matriz de transição de Markov). No intervalo de nove anos, houve mais de $40 \mathrm{~km}^{2}$ de perda de vegetação densa, mais de $60 \mathrm{~km}^{2}$ de perda de vegetação rasteira e quase $60 \mathrm{~km}^{2}$ de expansão da área urbana. Esta última se ampliando para locais com alta suscetibilidade à inundação.

Palavras-chave: Inundação, LCM, Mudanças de Uso e Cobertura do Solo, Município de Duque de Caxias.

Abstract: The number of natural disaster events has increased over time in Brazil and all the world. In the Brazilian context, there is an expressive occurrence of hydrological events such as floods, landslides and droughts. This article relates land use and land cover changes in the Duque de Caxias city, often affected by flood events, between 2007 and 2016 (period within the validity of the second county director plan), with the result of the mapping of the susceptible areas to the flood, carried out by the CPRM (2013). The changes were inferred through the Land Change Modeler (LCM) model, and the input inputs correspond to the land use and cover maps supervised with the use of the CART, algorithm in the Google Earth Engine platform, using Landsat 5 images, sensor TM, bands 4 (near infrared), 3 (red) and 2 (green), and Landsat 8, OLI sensor, Bands 5 (near infrared), 4 (red) and 3 (green), both with resolution of 30m x 30m . The classes "urban", "dense vegetation", "undergrowth" and "soil exposed" were analyzed. This work aims to identify which classes have obtained the greatest changes in the period of analysis if they tend to occur in areas classified as high susceptibility to flood and the probability of one class becoming another in 2026 (through the Markov transition matrix). In the interval of nine years, there was more than $40 \mathrm{~km}^{2}$ of dense vegetation loss, more than $60 \mathrm{~km}^{2}$ of undergrowth loss and almost $60 \mathrm{~km}^{2}$ of urban area expansion. The latter is expanding to places with high susceptibility to flooding. 
Keywords: Flood, LCM, Land Use and Land Cover Change, Duque de Caxias' County.

\section{Introdução}

O espaço está em constante transformação por motivações naturais e antrópicas. Estas, intensificadas pós Revolução Industrial, têm contribuído com o aumento das ocorrências de desastres naturais relacionados à inundação, pois fatores como adensamento de residências, pavimentação de ruas, ocupação de planícies de inundação, retilinização de cursos d'água entre outros, intensificados pelo crescimento demográfico, contribuem com a redução da eficiência de drenagem da água em locais desprovidos de obras hidráulicas que visem um eficaz escoamento da mesma. Neste sentido, diante de chuvas mais intensas, a água não infiltra no solo e se direciona as partes mais baixas da cidade, onde, em alguns casos, se encontra com rios ou córregos e ocasiona as inundações (SANTOS, 2014).

Refletindo sobre o contexto brasileiro, mais especificamente o município de Duque de Caxias (RJ), que a partir da década de 40 passa por significativas modificações em seu espaço, nota-se que a presença das ferrovias e posteriormente da rodovia Washington Luiz atraíram indústrias como a antiga Fábrica Nacional de Motores (FNM), Refinaria Duque de Caxias (REDUC) entre outras pela viabilidade de chegada de subsídios para seu funcionamento e facilidade de dispersão de seus produtos. Em virtude do crescimento industrial e dos serviços que foram implantados para fornecer subsídios às indústrias, ao longo da segunda metade do século XX, Caxias deixa de ser apenas cidade dormitório atraindo trabalhadores para os empregos que surgem no município (COSTA, 2009).

A expansão demográfica se direcionou para locais inapropriados, devido à falta de planejamento e fiscalização, ocupando "terrenos de solos hidromórficos, íngremes e de planícies de inundação, tão comuns no municipio, sem as intervenções necessárias" (OSCAR JÚNIOR, 2015, p.192). Devido ao relevo, os bairros do terceiro e quarto distritos são os mais afetados. E os problemas de drenagem são os principais fatores, desde a década de 1950, no primeiro distrito do município (OSCAR JÚNIOR, 2015). Segundo Luz Barcellos et al. (2016), os maiores índices de desastres naturais relacionados à inundação, em Duque de Caxias, ocorrem durante a estação verão caracterizada por um período chuvoso sobre influência da Zona de Convergência do Atlântico Sul (ZCAS).

Estes desastres naturais impactam direta e indiretamente à população. O município de Duque de Caxias apresenta mais de oito décadas de relatos de pessoas desabrigadas, desalojadas, desaparecidas, mortas, prédios comerciais afeados, colégios sem funcionar por abrigarem pessoas atingidas pelo desastre, entre outros (OSCAR JÚNIOR, 2014; LUZ BARCELLOS et al., 2016; VISSIRINI et al., 2016). Foram elaborados instrumentos para minimizar os impactos das inundações como o Plano Municipal para Redução de Risco de Desastre de Inundação e o Plano Diretor de Recursos Hídricos da Bacia do Rio Iguaçú-Sarapuí, entretanto, a população do município continua sendo afetada pelas precipitações mais volumosas (VISSIRINI et al., 2016).

As inundações causam impactos de diversas dimensões, desde a perda de bens materiais até a perda de vidas. Nesta perspectiva, é fundamental a utilização de instrumentos que ajudem a gerir melhor o espaço geográfico para que os desastres naturais não ganhem magnitude causando grandes prejuízos à população (RODRIGUEZ et al., 2017).

Neste sentido, a análise multitemporal das mudanças de uso e cobertura da terra através do modelo Land Change Modeler (LCM) aliada ao mapeamento de suscetibilidade à inundação são recursos que podem contribuir com a temática dos desastres naturais, visto que os mesmos possibilitam inferir quais classes de uso e cobertura estão sobre áreas de alta suscetibilidade. Os modelos de predição futura contribuem, inclusive, para calcular as possíveis perdas econômicas como ressaltam Yulianto et al. (2016), além de auxiliar no planejamento territorial (SANTOS; PIROLI, 2015; ANDRADE et al., 2016; MENESES et al., 2018).

Desta forma, este artigo apresenta uma análise da relação da mudança de uso e cobertura da terra com as áreas de alta suscetibilidade à inundação no município de Duque de Caxias (RJ), buscando elencar as mudanças dos usos e coberturas da terra que estão sobre áreas de alto risco de inundação, dando destaque para as áreas urbanas, devido à grande presença de pessoas que podem estar sobre locais com alta suscetibilidade de serem afetados por inundações. E, também, devido aos desastres naturais serem caracterizados como fenômenos que afetam áreas com ocupação antrópica (TOMINAGA, 2009). 


\section{2. Área de Estudo}

O recorte espacial utilizado como laboratório das análises propostas está localizado na região metropolitana do estado do Rio de Janeiro. Possui 467,6 $\mathrm{km}^{2}$ de área e 890.997 habitantes, no ano de 2017, segundo dados do IBGE. O município faz divisa com as cidades de Nova Iguaçu, Belford Roxo, São João de Meriti, Rio de Janeiro, Magé, Petrópolis e Miguel Pereira. Possui quatro distritos, a saber: Duque de Caxias ( $1^{\circ}$ distrito), Campos Elíseos ( $2^{\circ}$ distrito), Imbariê ( $3^{\circ}$ distrito) e Xerém ( $4^{\circ}$ distrito), como pode ser observado na Figura 1.

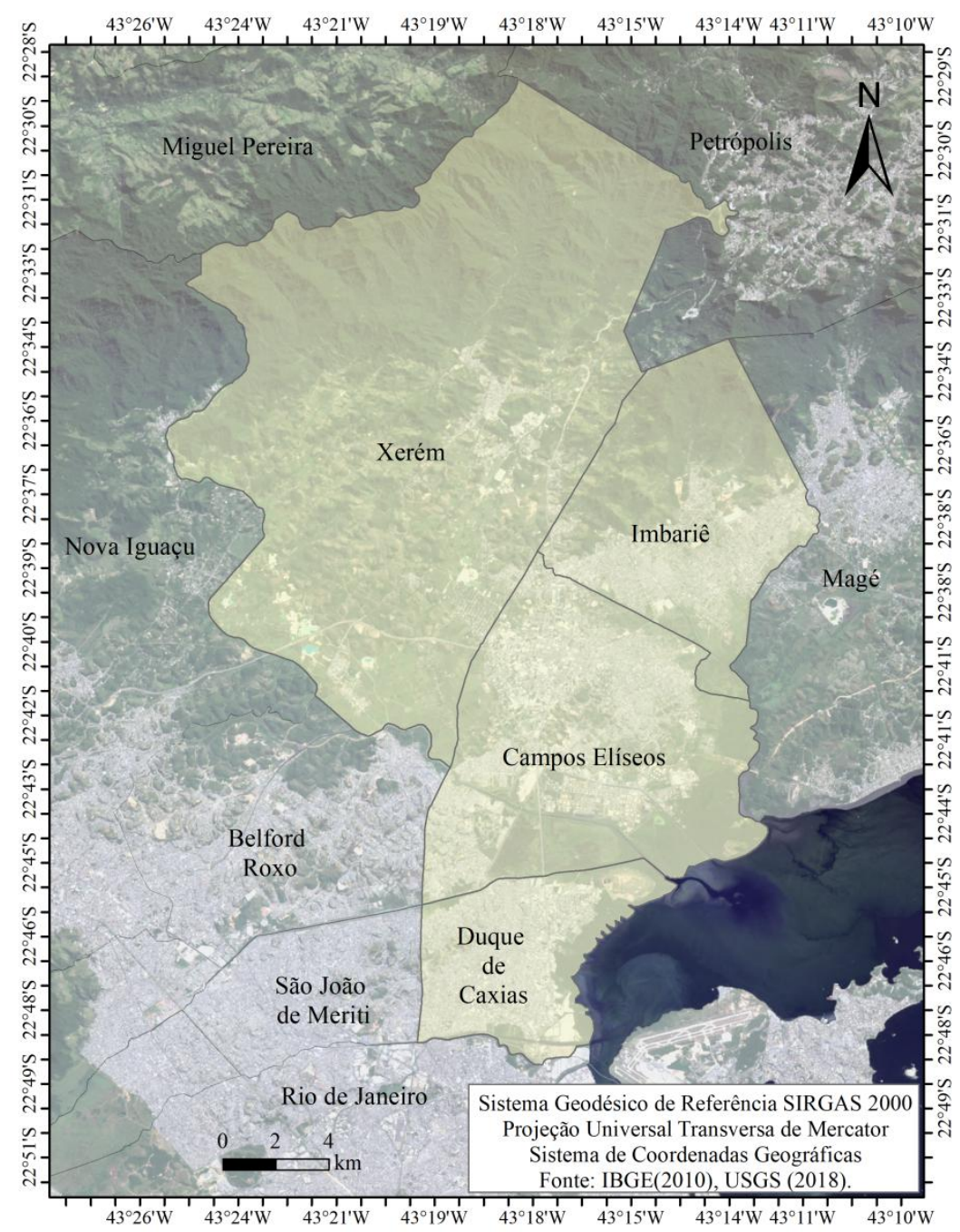

Figura 1: Localização da área de estudo.

O município de Duque de Caxias está inserido na Baixada Fluminense e como o próprio nome indica, seu território faz parte de uma área de baixada apresentando as maiores altitudes no seu limite norte onde se encontra com a Serra do Mar. Os aspectos fisiográficos do município corroboram para que o mesmo apresente condições propícias à ocorrência de eventos de inundação. A proximidade com o litoral gera umidade que se desloca para o continente. Esta, por sua vez, contribui com as chuvas orográficas que ocorrem em virtude da colisão das nuvens de chuva com a barreira orográfica da Serra do Mar (SOBRAL, 2018). Ao Norte do município está a Reserva Biológica do Tinguá que possui boa parte dos seus 24.812,9 hectares de extensão de Mata Atlântica, segundo dados do ICMBio, no quarto distrito de Duque de Caxias.

Diretamente relacionados com os eventos de inundação, os rios que drenam Duque de Caxias estão inseridos em três principais bacias hidrográficas: Iguaçu-Sarapuí, Estrela e São João de Meriti, respectivamente $38 \%, 47,9 \%$ e $7,1 \%$ da área do município, além de outras pequenas porções continentais com drenagem direta para a Baía de Guanabara (Plano Municipal de Saneamento Básico do Município de Duque de Caxias). Por sua vez, a área de estudo se encontra dentro da Região Hidrográfica V (RH V) instituída pela resolução número 107 de maio de 2013 do Conselho Estadual de Recursos Hídricos. 
Com base no mapeamento de suscetibilidade à inundação do CPRM, pode-se perceber que um percentual de $30 \%$ do município, correspondente a uma área de $140,2 \mathrm{~km}^{2}$, apresenta alta suscetibilidade à inundação; $11,3 \%\left(52,7 \mathrm{~km}^{2}\right)$, média suscetibilidade e; $2,8 \%\left(13,1 \mathrm{~km}^{2}\right)$, baixa suscetibilidade.

\section{Materiais e Método}

Com o intuito de analisar a dinâmica do uso e cobertura da terra entre 2007 (Instante Inicial: T1) e 2016 (Instante Final: T2) com previsões para 2026 (Instante Estimado: T3), e sua relação com as áreas suscetíveis à inundação, o presente trabalho passou por cinco etapas, a saber: levantamento do banco de dados geográficos para realização da pesquisa (etapa 1); classificação do uso e cobertura da terra (etapa 2); pósclassificação de imagens (etapa 3); uso do modelo LCM (etapa 4) e; sobreposição dos resultados às áreas de alta suscetibilidade à inundação (etapa 5). Estas serão abordadas nos subtítulos a seguir.

\subsection{Banco de Dados Geográficos}

Para execução deste trabalho, foram utilizadas imagens de satélite, base cartográfica do IBGE e mapeamento da suscetibilidade à inundação elaborado pelo Serviço Geológico do Brasil (CPRM).

Para inferir as mudanças ocorridas entre dois momentos estabelecidos no tempo pelo modelo Land Change Modeler (LCM), são necessários dois produtos espacializados que estejam dentro do intervalo de tempo que se pretende analisar. Este compreende o período de estudo do analista e apresenta o contexto histórico que norteará a elaboração de cenários.

De preferência, os produtos devem estar o mais próximo do ano de início e fím do intervalo. Nesse sentido, foram adquiridas duas imagens no site da USGS. Uma do ano de 2007 (Landsat 5) e outra do ano de 2016 (Landsat 8, também chamado de LDCM - Landsat Data Continuity Mission). Foram utilizadas as bandas de 30m de resolução espacial das imagens do grupo (Landsat Collection 1 Level 1), que segundo o site da NASA, são cenas Landsat com a mais alta qualidade de dados, consideradas adequadas para análise de processamento de séries temporais. Inclui dados processados de precisão com radiometria bem caracterizada e inter-calibrados através dos diferentes sensores Landsat. Todos os dados Landsat de Nível 1 podem ser considerados calibrados radiometricamente e geolocalizados, consistentemente em toda a coleção para todos os sensores. O critério para a escolha das imagens, além da qualidade, foi que as mesmas estivessem dentro do período do verão, pois é quando são observados os maiores índices de eventos de inundação. Entretanto, para o ano de 2016, o mês de abril, mais próximo deste período, foi o que apresentou imagens com menor cobertura de nuvens.

Para a delimitação da área de estudo, foi utilizada a base cartográfica do IBGE (2010) na escala 1: 250.000, Sistema de Projeção UTM e Sistema Geodésico de Referência SIRGAS 2000. Dessa base, além do limite do município de Duque de Caxias, foram utilizados os limites dos municípios vizinhos (para elaboração do mapa de localização) e dos distritos (no mapa de localização e junto a alguns produtos gerados no modelo LCM).

Por sua vez, a carta de suscetibilidade a movimentos gravitacionais de massa e inundação, elaborado pelo CPRM, disponível no próprio site do Serviço Geológico do Brasil, na escala 1:25.000, foi utilizada para sobrepor aos produtos gerados no LCM, com o objetivo de compreender a dinâmica do uso e cobertura da terra dentro das áreas de alta suscetibilidade à inundação. Segundo o CPRM, o zoneamento apresentado é de nível básico (apresenta as classes alta, média e baixa suscetibilidade) e está fundamentado em fatores naturais predisponentes espacializáveis, obtidos por meio de compilação e tratamento de dados secundários disponíveis e validação em campo. Para este trabalho foi utilizado apenas os polígonos de alta suscetibilidade à inundação.

\subsection{Classificação do Uso e Cobertura da Terra}

Os mapeamentos do uso e cobertura da terra foram realizados em duas imagens de satélite através de classificação supervisionada com o uso do algoritmo CART, na plataforma Google Earth Engine, para analisar as mudanças entre as classes no intervalo de 2007 a 2016. Estes foram gerados utilizando imagens Landsat 5 e Landsat 8. Foram mapeadas as classes água, vegetação densa, vegetação rasteira, área úmida, urbano e solo exposto. A classificação supervisionada exige o conhecimento prévio sobre a localização de algumas amostras das classes que serão mapeadas e se baseia no pressuposto de que cada classe espectral pode ser descrita por amostras fornecidas pelo analista (NOVO, 2010).

Para o mapeamento do uso e cobertura da terra do ano de 2007, foi utilizada imagem Landsat 5 com o empilhamento das bandas de 30m de resolução espacial e composição colorida $(4,3,2)$ no padrão RGB. 
Na classificação do ano de 2016 foi utilizada imagem Landsat 8, empilhamento das bandas de 30m de resolução espacial e, combinação $(5,4,3)$ no padrão $R G B$, tendo sequência numérica diferente devido à inclusão de novas bandas no satélite LDCM.

As classificações foram avaliadas através de pontos aleatórios gerados pela ferramenta Create Random Points do ArcGis, cujas quantidades de pontos variaram proporcionalmente ao tamanho da área de cada classe. Os dois mapeamentos obtiveram índice Kappa igual a 0,8, o que significa, segundo Fonseca (2000), um desempenho muito bom da classificação. Apresentaram também o valor de 0,9 na inferência da Exatidão Global.

\subsection{Pós-classificação de Imagem}

Os usos e coberturas da terra passaram por alguns tratamentos antes de serem inseridos no modelo LCM para o mapeamento das transições ocorridas entre as classes. $\mathrm{O}$ arquivo matricial foi convertido para estrutura de dados gráficos vetorial. E, em seguida, foi extraída a área de estudo, o que proporcionou uma maior velocidade nos processamentos posteriormente realizados. O arquivo ainda passou por edições dos conteúdos da tabela com o intuito de viabilizar a comparação entre os usos e coberturas da terra. Sendo assim, a nomenclatura destes foi padronizada e os polígonos gerados foram generalizados com base nos nomes das classes.

Para corrigir algumas confusões de classe que ocorreram no mapeamento, foram feitas edições vetoriais manuais para as classes urbano e área úmida. A classe urbano foi refinada comparando a área classificada como urbano em 2007 com a classificação de 2016 e imagens de alta resolução espacial. Nessa contraposição das classificações, o que não foi mapeado como urbano em 2016 foi analisado em imagens de satélite e os polígonos das duas classificações foram ajustados com as classes condizentes. Por sua vez, a classe área úmida foi ajustada sobrepondo-a a uma imagem de alta resolução espacial.

\subsection{Land Change Modeler (LCM)}

As mudanças de uso e cobertura da terra entre os anos de 2007 e 2016 foram inferidas através do modelo Land Change Modeler presente no software IDRISI 17.0. Com base nesse modelo, foram obtidos os gráficos de perdas e ganhos, modelos de detecção de mudanças, modelo de tendência espacial de mudança e a matriz de transição com as probabilidades de mudança (baseada nas Cadeias de Markov).

O gráfico de perdas e ganhos apresenta o quanto cada classe de uso e cobertura ganhou e perdeu área dentro do intervalo de tempo analisado. $\mathrm{O}$ mesmo possibilita apreender quais classes contribuíram para as alterações observadas no momento T2. Vale ressaltar que as análises foram feitas utilizando classificação supervisionada do uso e cobertura da terra, com imagens de satélite, que é uma generalização da realidade. Neste procedimento, embora com uma boa avaliação da exatidão global e do índice kappa, ocorreram algumas confusões de classificação entre os alvos analisados, mas que não prejudicaram alcançar os objetivos do trabalho.

O modelo de detecção de mudanças apresenta o local em que uma classe mudou para outra. Diversos resultados podem ser gerados combinando as classes trabalhadas. Para esta pesquisa foram gerados modelos de mudança, considerando as transições vegetação rasteira para urbano, vegetação densa para urbano e solo exposto para urbano. Estas transições foram escolhidas pelos seguintes critérios: i) após observar, no gráfico de perdas e ganhos, que a classe urbano foi a que teve um maior ganho de área; ii) as classes vegetação rasteira, vegetação densa e solo exposto foram as que mais contribuíram com a expansão da área urbana; iii) e pelo fato de a classe urbano ser importante para compreender a dimensão do impacto das inundações à população.

Por sua vez, os modelos de tendência espacial de mudança indicam a direção para onde as mudanças de uso e cobertura da terra estão se dirigindo. Para este tipo de produto, foram trabalhadas as mesmas transições utilizadas nos modelos de detecção de mudanças.

Por fim, o último produto gerado foi a matriz de transição (MT) com as probabilidades de mudança de uma classe para outra, em um instante estimado (T3), referente ao intervalo de dez anos, através das Cadeias de Markov, cujas probabilidades de transição são derivadas de amostras relativas ao instante de tempo T1 e T2. A seleção desses instantes é fundamental, pois ela vai definir os futuros, a partir da amostra apresentada. Através da alteração observada no tempo " $\mathrm{t}$ " e no tempo " $\mathrm{t}+1$ " faz-se a previsão para o futuro (SOARESFILHO, 1998; BACA et al., 2007; RUHOFF et al., 2010; BESER DE DEUS, 2013). 
Especificamente sobre as Cadeias de Markov, pode-se dizer que são uma formalização, como uma máquina de mudança de estados, de modelagem empírica de sistemas que descrevem o mesmo como um processo estocástico (em teorias de probabilidade). A MT, baseada em Markov, é uma matriz quadrada MxM, em que os elementos representam a probabilidade de mudança de um tema para outro. Esta compreende uma representação matemática das cadeias de Markov (MARKOV, 1971; HARVEY, 1974; SILVA; SOUZA, 1992; BRIASSOULIS, 2000; HAYKIN, 2001; BACA, 2002; BACA et al., 2007; PEDROSA; CÂMARA, 2007; CONSTANTINOU, 2007; RUHOFF et al., 2010; GRIGOLETTI, 2012).

\subsection{Mudança de Uso e Cobertura da Terra X Suscetibilidade à Inundação}

A última etapa da elaboração deste trabalho consistiu em sobrepor os vetores de alta suscetibilidade à inundação, da carta de suscetibilidade a movimentos gravitacionais de massa e inundação, elaborado pelo CPRM, aos modelos de tendência espacial de mudança. Visando a elaboração de um produto que auxiliasse o planejamento para áreas que tenderiam a ser urbanas com o passar do tempo.

Com a associação destas informações foi possível inferir, através de análise visual, se a mancha urbana está convergindo para áreas classificadas com alta suscetibilidade à inundação, conhecimento indispensável para minimizar os impactos que os eventos de inundação podem causar à população, como perdas materiais, prejuízos econômicos e perda de vidas humanas.

\section{Análise dos Resultados}

O município de Duque de Caxias tem sido afetado por eventos de inundação com maior frequência, ao longo do tempo, favorecidos pelas formas de uso e ocupação da terra, que suprimem a vegetação e mudam as feições dos rios para construção de habitações, acarretando transtornos à sociedade (Oscar Júnior, 2013). Buscando analisar a dinâmica dos usos e coberturas da terra e a relação da direção das transições com as áreas de alta suscetibilidade à inundação, utilizou-se o modelo LCM e a sobreposição do mapeamento da suscetibilidade à inundação em alguns produtos gerados pelo modelo.

A espacialização do uso e cobertura da terra para o momento inicial apresenta a maior parte da área do município com cobertura vegetal densa $(61,5 \%)$, seguida de vegetação rasteira $(20,3 \%)$ e uso urbano $(12,6 \%)$ como pode ser observado na Tabela 1 e Figura 2A. O município de Duque de Caxias apresentou constante expansão demográfica após sua emancipação, em 1943, do munícipio de Nova Iguaçu. Na década de 2000, por exemplo, a população era composta por 775.456 habitantes e no último censo demográfico do IBGE (2010) constatou-se que a população chegara a 855.048 habitantes.

$\mathrm{O}$ acréscimo da população se concentrou principalmente no primeiro e segundo distritos, mas a expansão da mancha urbana também se direciona ao terceiro e quarto distritos. Para o segundo ano de análise observase um declínio nas áreas de cobertura vegetal densa e rasteira, solo exposto e área úmida e aumento na área urbana (Tabela 1 e Figura 2B).

Tabela 1: Área ocupada pelas classes de uso e cobertura da terra no município de Duque de Caxias.

Área Ocupada pelas Classes de Uso e Cobertura da Terra

\begin{tabular}{ccccc}
\hline Classes & \multicolumn{2}{c}{$\mathbf{2 0 0 7}$} & \multicolumn{2}{c}{$\mathbf{2 0 1 6}$} \\
Água & $\mathbf{k m}^{\mathbf{2}}$ & $\mathbf{( \% )}$ & $\mathbf{k m}^{\mathbf{2}}$ & $\mathbf{( \% )}$ \\
Área Úmida & 2,2 & 0,5 & 3,1 & 0,7 \\
Solo Exposto & 29,3 & 6,3 & 22,1 & 4,7 \\
Urbano & 3,8 & 0,8 & 3,3 & 0,7 \\
Vegetação Densa & 58,9 & 12,6 & 114,6 & 24,5 \\
Vegetação Rasteira & 278,4 & 61,5 & 253,2 & 54,2 \\
\hline
\end{tabular}





\section{Legenda}

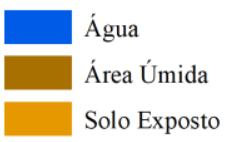

Solo Exposto
Urbano

Vegetação Densa

Vegetação Rasteira
Projeção Universal Transversa de Mercator

Sistema Geodésico de Referêcia SIRGAS 2000 Coordenadas Métricas

Fonte: Landsat 5 (2007), Landsat 8 (2016), IBGE (2012).

Figura 2: Uso e cobertura da terra no município de Duque de Caxias.

\subsection{Gráfico de Perdas e Ganhos}

O gráfico de perdas e ganhos (Figura 3) indica que as classes vegetação rasteira, densa e área úmida foram as que mais perderam área no intervalo de nove anos. Entretanto, as classes vegetação rasteira e vegetação densa tiveram uma compensação de parte da área perdida com seu estabelecimento em outros locais no município. Neste mesmo intervalo de tempo, a classe urbano foi a que teve uma expansão significativa da área. Este resultado converge com modelo elaborado por Delaneze et al (2014) que prevê o aumento da área construída e redução da vegetação arbórea, ao longo dos anos, entre 2010 e 2020.

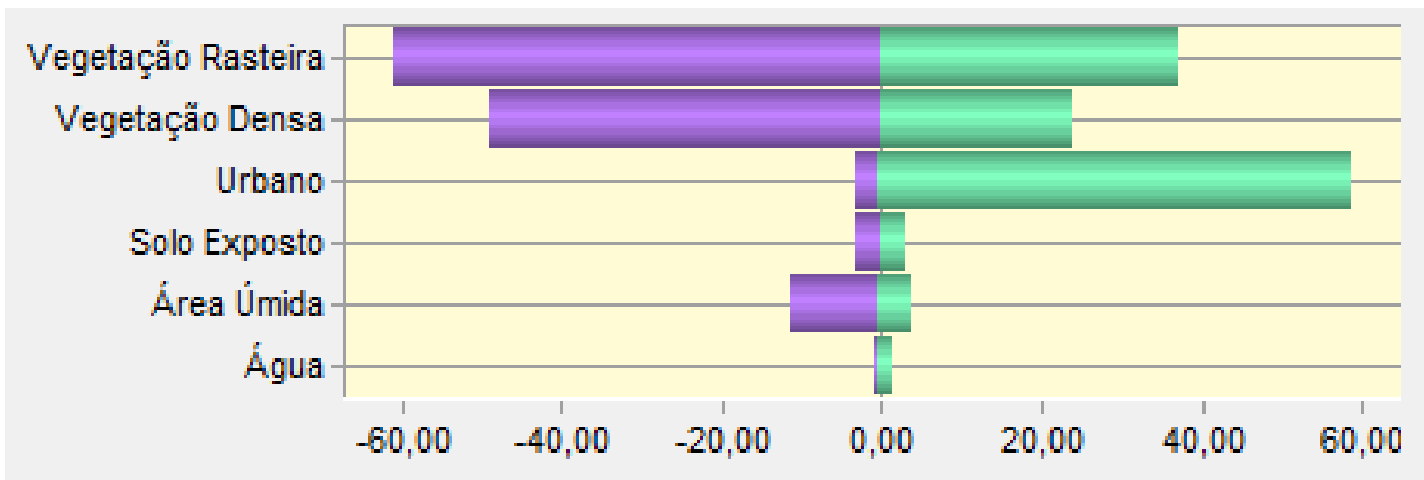

Figura 3: Gráfico de perdas e ganhos das classes de uso e cobertura da terra em km². 
Visto que o uso urbano foi o que mais se expandiu sobre outros usos e coberturas da terra no intervalo de tempo analisado, no gráfico de contribuições (Figura 4) observa-se que o urbano ocupou, em maior proporção, respectivamente, áreas com vegetação rasteira, vegetação densa e solo exposto.

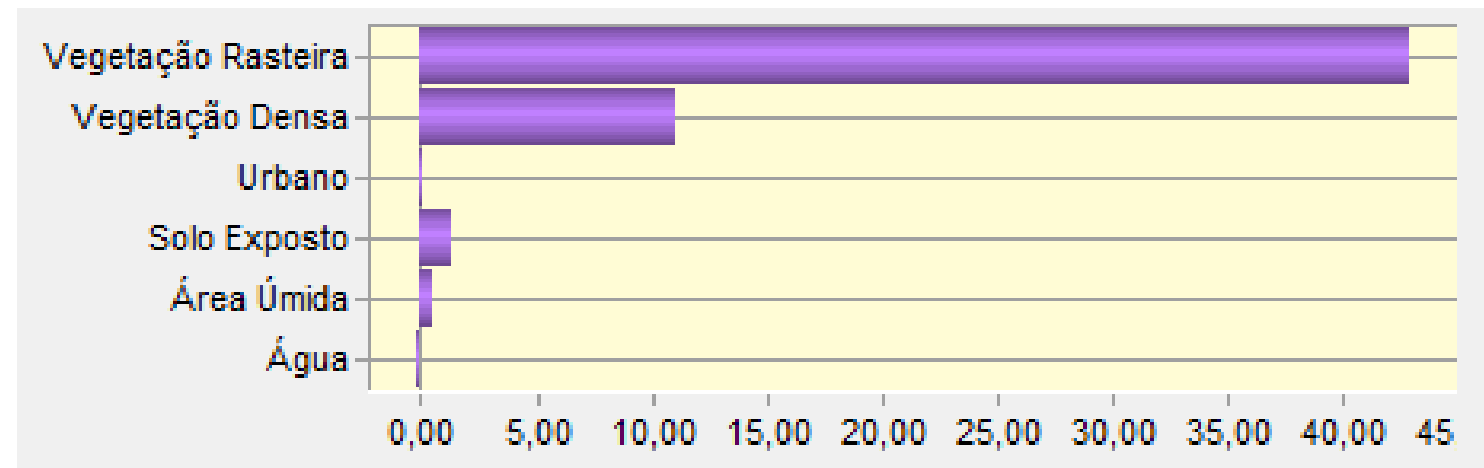

Figura 4: Gráfico com as classes que contribuíram com as mudanças na classe urbano em $\mathrm{km}^{2}$.

Ao longo da principal rodovia do município (Rodovia Washington Luiz), por exemplo, galpões, grandes redes atacadistas e outras obras têm sido realizadas. Em virtude disso, a cobertura vegetal às margens da via é afetada, como pode ser observado na (Figura 5), que apresenta uma área destinada à construção de uma central de abastecimento.

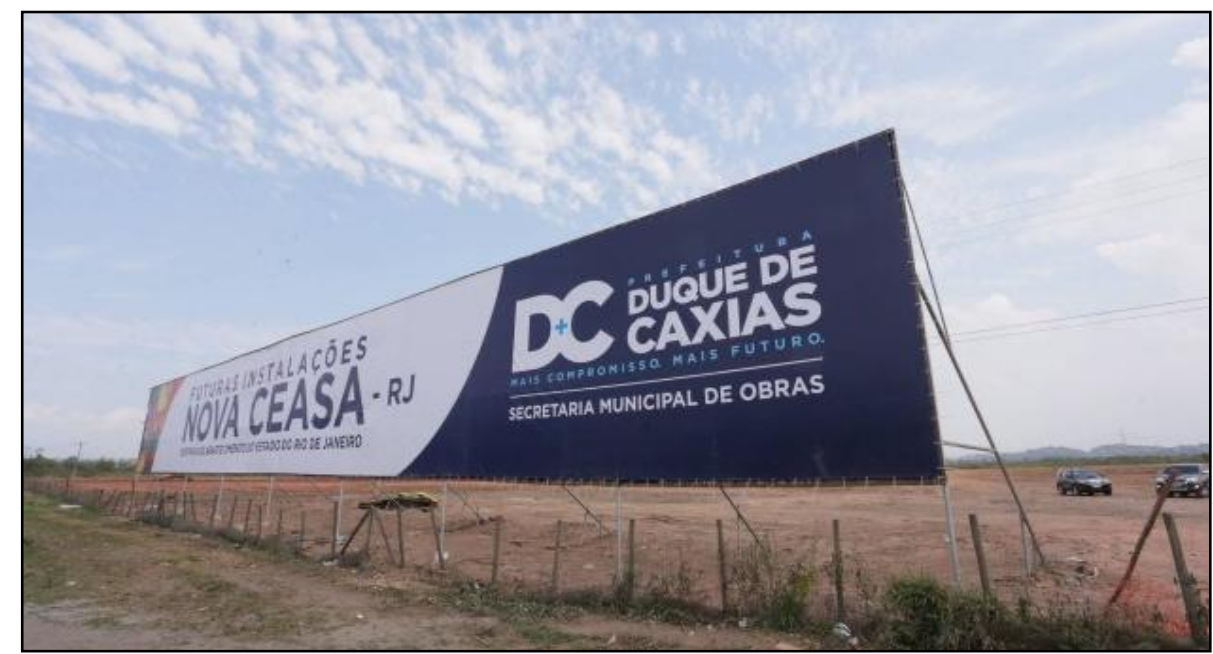

Figura 5: Área destinada à construção de uma CEASA. Fonte: Jornal Extra de 26/09/2017. Acesso em: $30 / 07 / 2018$.

Tendo-se constatado as principais mudanças que ocorreram entre 2007 e 2016, o próximo tópico apresentará a alocação espacial dessas mudanças.

\subsection{Modelo de Deteç̧ão de Mudanças}

Com o modelo de detecção de mudanças é possível observar onde ocorreram as transições de uso e cobertura da terra. Na Figura 6 são apresentados três mapas que indicam os locais onde a vegetação rasteira, vegetação densa e solo exposto, respectivamente, foram substituídos por área urbana. Nestes foi inserido o limite da Reserva Biológica do Tinguá (Rebio Tinguá). É possível que esta funcione como "amortecimento" para a expansão da mancha urbana, pois nas proximidades da mesma observa-se uma redução na intensidade das mudanças. 



Vegetação Rasteira
para Urbano

Legenda

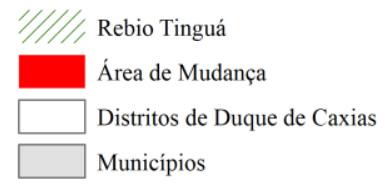

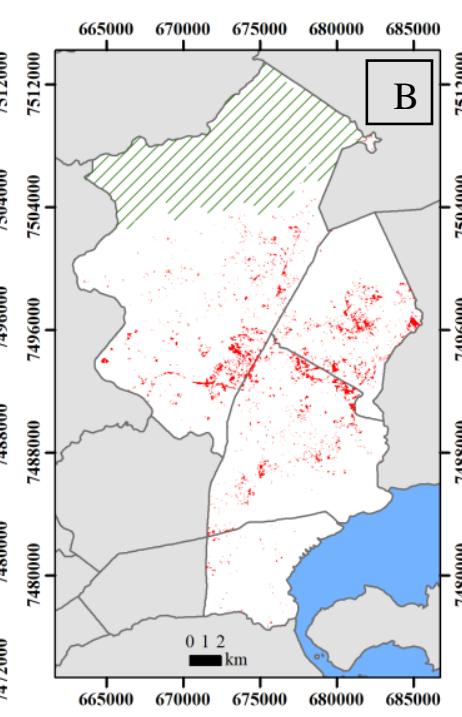
Vegetação Densa
para Urbano

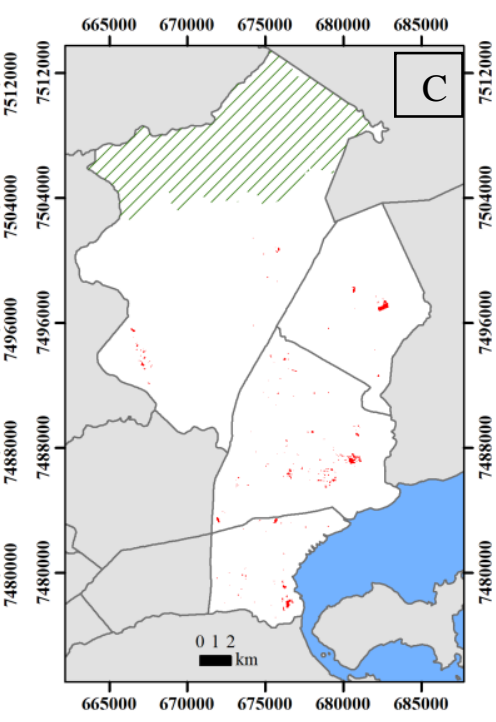

Solo Exposto para Urbano
Projeção Universal Transversa de Mercator Sistema Geodésico de Referência SIRGAS 2000 Coordenadas Métricas
Fonte: IBGE (2012) e ICMBio (2014)

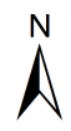

Figura 6: Áreas onde houve mudanças de vegetação rasteira, densa e solo exposto para urbano.

A transição vegetação rasteira (Figura 6A) para área urbana ocorreu com mais intensidade no segundo e terceiro distritos. Somam-se $42,9 \mathrm{~km}^{2}$ de expansão da área urbana para área de vegetação rasteira. A área urbana cresceu $11 \mathrm{~km}^{2}$ sobre locais cobertos por vegetação densa no município (Figura $\mathbf{6 B}$ ). Segundo Puggian e Raulino (2015), em 2014 mais de 160 árvores foram cortadas no centro da cidade para a construção de um shopping center. Esta transição se concentra no segundo, terceiro e quarto distritos, os dois últimos ainda apresentam a maior parte da vegetação densa municipal.

A supressão de locais com solo exposto em função da expansão da área urbana (Figura $6 C$ ) ocorreu em todo o município, mas no segundo distrito observa-se maior dispersão dessa transição. $\mathrm{O}$ urbano se consolidou em 1,3km² de área de solo exposto. A Figura 7 apresenta um exemplo desta transição, observada no ano de 2018, no quarto distrito de Duque de Caxias. A área de solo exposto, na imagem, é um loteamento destinado à construção de novas residências. Lima e Souza (2014), por sua vez, destacam o crescimento de condomínios no bairro de Mantiquira, que é uma parcela do território de Xerém com melhor infraestrutura urbana.

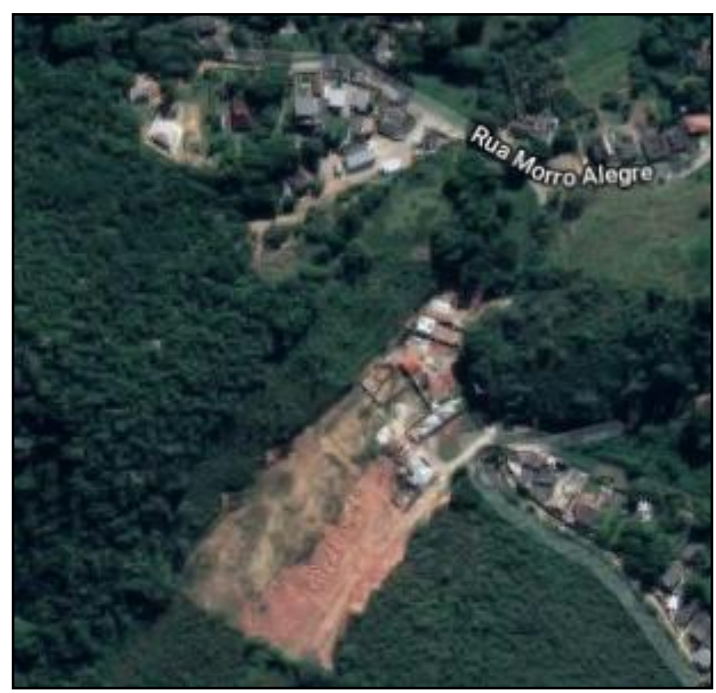

Figura 7: Abertura de loteamento no $4^{\circ}$ distrito de Duque de Caxias. Fonte: Google Earth. 


\subsection{Modelo de Tendência de Mudança}

O modelo de tendência de mudança indica a direção em que as transições de uso e cobertura da terra tendem a seguir. Foram gerados três modelos de tendência (Figura 8) para analisar a possibilidade do direcionamento da expansão da mancha urbana por meio da supressão da classe vegetação rasteira, vegetação densa e solo exposto.

A este modelo foi sobreposto a delimitação da área de alta suscetibilidade à inundação, buscando, entre outros elementos, identificar futuras áreas urbanas que tendem a se estabelecer em locais com alta suscetibilidade à inundação.

O primeiro modelo (Figura $8 \boldsymbol{A}$ ) apresenta a direção que a mancha urbana tende a seguir através da contribuição da classe vegetação rasteira. Observa-se forte tendência no segundo e terceiro distritos. Esta tendência perde força na direção do primeiro e quarto distritos. Soma-se a isso, a maior intensidade da tendência de mudança em locais com alta suscetibilidade à inundação.

O modelo de tendência da transição de vegetação densa para área urbana (Figura 8B) indica alta possibilidade de ocorrer no segundo e terceiro distritos e um direcionamento ao quarto distrito. Observa-se neste modelo que a Rebio Tinguá possivelmente cumpre um papel de barreira para a expansão da mancha urbana. A maior parte da área de alta suscetibilidade à inundação está sobre locais com forte tendência de se tornar área urbana. Vale ressaltar que o quarto distrito não possui uma urbanização consolidada em todo seu território. Logo, isso possibilita realizar um planejamento do uso da terra, para que no futuro, com a expansão da mancha urbana, a população não seja impactada como no evento que ocorreu em $2013 \mathrm{em}$ Xerém, quando 200 pessoas foram afetadas e 3 pessoas perderam suas vidas (LUZ BARCELLOS et al., 2016; OSCAR JÚNIOR, 2013).

A tendência da classe solo exposto ceder espaço para área urbana (Figura $8 C$ ) é forte no primeiro e segundo distritos e se direciona ao terceiro distrito. A alta tendência converge com locais de alta suscetibilidade à inundação.
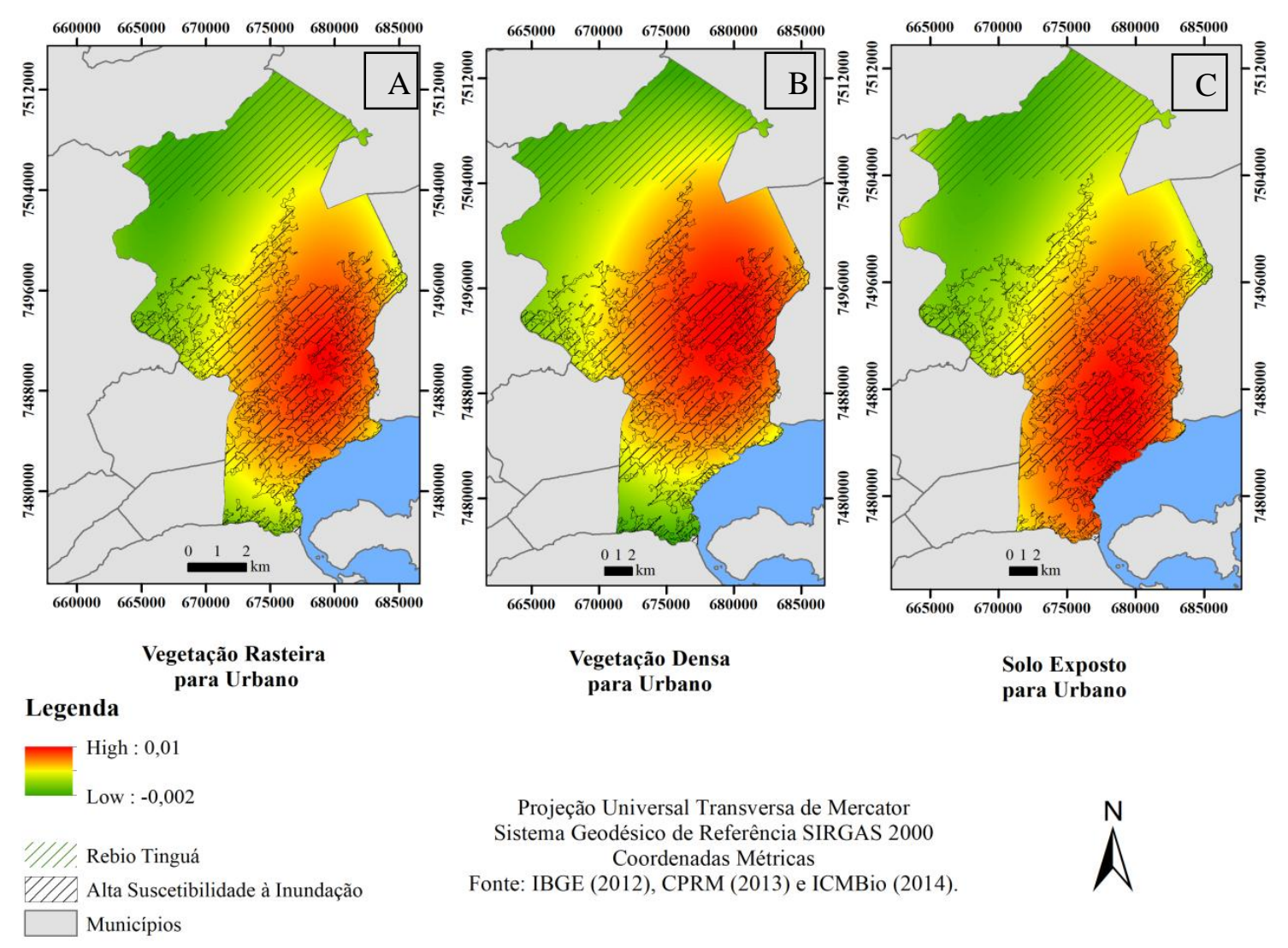

Figura 8: Tendência de mudança das classes vegetação rasteira, vegetação densa e solo exposto para área urbana.

Todos os modelos de tendência de mudança apresentaram que a mancha urbana tende a se direcionar para locais com alta suscetibilidade à inundação. $O$ primeiro e segundo distritos apresentam urbanização consolidada, entretanto, o terceiro e quarto distritos possuem espaços com possibilidade de serem planejados 
para que a ocupação não ocorra em locais de risco, não aumente o número de pessoas vulneráveis à inundação nem contribua com a maior frequência do evento. O modelo também sinaliza que as tendências de mudança são mais fortes próximas às áreas urbanas, concretizando a Lei de Tobler, que afirma que tudo está relacionado com todo o resto, mas coisas próximas estão mais relacionadas do que as mais distantes (TOBLER, 1970).

\subsubsection{Matriz de Transição}

A matriz de transição, baseada em Markov, foi o último produto gerado (Tabela 2). Esta possibilita conhecer a probabilidade de uma classe mudar para outra ou permanecer a mesma em um dado ano. Nesta perspectiva, foi feita uma previsão, de médio prazo, considerando um intervalo de dez anos. O ano de 2026 foi definido com base no ciclo de atualização do plano diretor municipal.

Tabela 2: Matriz de Markov.

\begin{tabular}{ccccccc}
\hline & Água & $\begin{array}{c}\text { Área } \\
\text { úmida }\end{array}$ & $\begin{array}{c}\text { Solo } \\
\text { exposto }\end{array}$ & Urbano & $\begin{array}{c}\text { Vegetação } \\
\text { densa }\end{array}$ & $\begin{array}{c}\text { Vegetação } \\
\text { rasteira }\end{array}$ \\
\hline Água & 0,5 & 0,2 & 0,0 & 0,1 & 0,2 & 0,0 \\
Área úmida & 0,0 & 0,6 & 0,0 & 0,0 & 0,4 & 0,0 \\
Solo exposto & 0,0 & 0,2 & 0,0 & 0,4 & 0,2 & 0,1 \\
Urbano & 0,0 & 0,0 & 0,0 & 0,9 & 0,0 & 0,0 \\
$\begin{array}{c}\text { Vegetação } \\
\text { densa }\end{array}$ & 0,0 & 0,0 & 0,0 & 0,0 & 0,8 & 0,2 \\
$\begin{array}{c}\text { Vegetação } \\
\text { rasteira }\end{array}$ & 0,0 & 0,0 & 0,0 & 0,6 & 0,2 & 0,3 \\
\hline
\end{tabular}

Quanto mais próximo de um, maior é a probabilidade de mudança ou permanência. Visto que para este trabalho a classe urbana é de maior interesse, em virtude da repercussão dos eventos de inundação para a população, a análise da matriz dará mais ênfase a esta classe.

As áreas de vegetação rasteira tendem a ser as maiores contribuintes da expansão urbana seguido da classe solo exposto. É nítido, ao se deslocar pelo município, locais que apresentam solo exposto e vegetação rasteira destinados a novos empreendimentos como construções de galpões e abertura de loteamento.

A probabilidade de em 2026 a vegetação rasteira continuar sendo o maior contribuinte para a expansão da mancha urbana ainda é majoritária diante das outras classes analisadas.

A matriz contribui para a reflexão de que as áreas de vegetação rasteira e solo exposto necessitam de uma atenção maior durante o planejamento e gestão do município, para que a expansão da mancha urbana evite locais de risco. Vale ressaltar que o plano diretor municipal, que desde 2016 não foi atualizado, é um instrumento importante para se traçar o rumo da expansão consciente da mancha urbana.

\section{Considerações Finais}

Este artigo propôs realizar uma análise da mudança de uso e cobertura da terra entre 2007 e 2016, do direcionamento dessas mudanças e da probabilidade de um uso ou cobertura se tornar outro no futuro, em médio prazo, para o ano de 2026. Todas essas análises foram pautadas visando contribuir com a produção de subsídios para um melhor planejamento e gestão municipal, em prol de minimizar os impactos causados por desastres naturais relacionados à inundação.

Neste sentido, a pesquisa apresentou o quanto cada classe ganhou e/ou perdeu área, indicando que as classes vegetação densa, vegetação rasteira e solo exposto contribuíram para a expansão da área urbana. Conhecer o direcionamento do urbano possibilita investigar se o mesmo se expandiu para locais com risco à inundação, o que possivelmente resultaria em um aumento do número de pessoas afetadas por desastres naturais relacionados à inundação. 
O modelo de tendência de mudança com a sobreposição da camada de alta suscetibilidade à inundação indicou que o crescimento urbano tendia a acontecer com mais intensidade sobre locais altamente suscetíveis ou convergindo para estes.

Com Markov foi gerada uma matriz de transição com o potencial de uma classe se tornar outra em um intervalo de dez anos. Este conhecimento possibilita monitorar a mesma para que esta alteração ocorra de forma ordenada, caso seja viável, ou aplicar medidas para frear esta mudança.

Diante de um contexto de um município que possui áreas altamente suscetíveis à inundação, monitorar o crescimento da mancha urbana para esses locais, para evitar a ocupação dos mesmos, contribui com a redução de impactos diretos desses eventos.

Recomenda-se que trabalhos como este detalhem as classes utilizadas, façam uso de modelos de alocação espacial e também sobreponham os resultados alcançados aos instrumentos vigentes de planejamento urbano e ambiental.

\section{Referências Bibliográficas}

ANDRADE, M. P. de; RIBEIRO, C. B. M; LIMA, R. N. S. et al. Modelagem Dinâmica da Mudança do Uso e Cobertura do Solo na Bacia Hidrográfica do Rio Paraíba do Sul a Partir de Imagens Modis e um Modelo de Sub-Regiões. Revista Brasileira de Cartografia (2016), N 68/5: 965-978. Sociedade Brasileira de Cartografia, Geodésia, Fotogrametria e Sensoriamento Remoto ISSN: 1808-0936.

BACA, J. F. M.; COELHO NETTO, A. L.; MENEZES, P. M. L. de. Modelagem da Dinâmica da Paisagem com Processos de Markov. (In): Meirelles, M.S.P.; Câmara, G.; Almeida, C.M. Geomática: modelos e aplicações ambientais . Embrapa Informação Tecnológica. Brasília, DF. 2007. 592p.

BACA, J. F. M. Dinâmica da Paisagem: métodos analíticos, modelos de classificação e simulação prognostica, sob a ótica geoecológica. Tese (Doutorado). Rio de Janeiro: UFRJ / Programa de pós-graduação em Geografia, 2002.

BESER DE DEUS, L. A. Espaço e Tempo como Subsídios à Construção de Cenários de Uso e Cobertura da Terra para o Planejamento Ambiental na Amazônia: O Caso da Bacia do Rio Acre. Tese (doutorado) - UFRJ, COPPE, Programa de Planejamento Energético, 2013.

BRASIL. Resolução CERHI-RJ $n^{\circ}$ 107, de 22 de maio de 2013. Aprova Nova Definição das Regiões Hidrográficas do Estado do Rio de Janeiro e Revoga a Resolução CERHI n ${ }^{\circ} 18$ de 08 de novembro de 2006. Órgão emissor: CERHI - Conselho Estadual de Recursos Hídricos. Disponível em: <http://www.inea.rj.gov.br/cs/groups/public/documents/document/zwff/mda5/ edisp/inea 009662.pdf>. Acesso em: 28.maio.2018

BRIASSOULIS, H. "Analysis of Land Use Change: Theoretical and Modeling Approaches". In: The Web Book of Regional Science, editor S. Loveridge, Regional Research Institute, West Virginia University, June 2000. http://www.rri.wvu.edu/WebBook/Briassoulis/contents.htm

CONSTANTINOU. Dinâmica Intra-Urbana: Aleatoriedade e Emergência de
Padrões Espaco-Temporais. Cadeias de Markov. 2007.

COSTA, P. A. Duque de Caxias $(\mathbf{R J})$ - de cidade dormitório à cidade do refino do petróleo: um estudo econômico-político, do início dos anos 50 ao início dos anos 1970. Tese (doutorado) - Universidade Federal Fluminense, Instituto de Ciências Humanas e Filosofia, Departamento de História, 2009.

DELANEZE, M. E; RIEDEL, P. S; MARQUES, M. L; FERREIRA, M. V. Modelagem Dinâmica Espacial para o Monitoramento do Crescimento Urbano no Entorno do Duto Orbel. Revista Brasileira de Cartografia (2014) No 66/3: 473-484 Sociedade Brasileira de Cartografia, Geodésia, Fotogrametria e Sensoriamento Remoto ISSN: 1808-0936.

FONSECA, L. M. G. Processamento digital de imagens. São José dos Campos: Instituto Nacional de Pesquisas Espaciais (INPE), 2000.

GRIGOLETTI, P. S. Cadeias de Makov. Escola de Informática - Universidade Católica de Pelotas (UCPel). Disponível em: <www.ufjf.br/epd042/files/2009/02/cadeiaMarkov.pdf >. Acesso em: julho de 2012.

HARVEY, D. Modelos de Evolução dos Padrões Espaciais na Geografia Humana. In: CHORLEY, R. J.; HAGGETT, P. Modelos Integrados em Geografia. Rio de Janeiro: Livros Técnicos e Científicos; São Paulo: Ed. da Universidade de São Paulo, 1974. 
HAYKIN, S. Redes neurais: Princípios e práticas. 2 edição. 900p. Traduzido: Paulo Martins Engel. Ed. Bookman. Porto Alegre - RS. 2001.

IBGE. Duque de Caxias. Disponível em: 〈https://cidades.ibge.gov.br/brasil/rj/duque-de-caxias/panorama $>$. Acesso em: 27.jul.2018.

ICMBIO. Tinguá Conserva Pedaço de Mata Atlântica. Disponível em: $<$ http://www.icmbio.gov.br/portal/ultimas-noticias/4-destaques/6978-tingua-conserva-pedaco-de-mataatlantica>. Acesso em: 28.jul.2018.

JORNAL EXTRA. Duque de Caxias inicia obra para construção de uma nova Ceasa no estado. Disponível em: <https://extra.globo.com/noticias/rio/duque-de-caxias-inicia-obra-para-construcao-de-umanova-ceasa-no-estado-21869361.html>. Acesso em: 30.jul.2018.

LIMA, A. A. M; SOUZA, A. P. de. Reflexões e Contribuições aos Estudos de Risco e Justiça Ambiental na Baixada Fluminense, Duque de Caxias-Rj. Revista Eletrônica História, Natureza e Espaço - ISSN 2317-8361 v. 3, n. 2 (2014). DOI: 10.12957/hne.2014.20271.

LUZ BARCELlOS, P. da C; SILVA, F. P. da; VISSIRINI, C. A. M; TERRA, J. M; DUTRA, M. R. F; AMARAL, I. C. F. do. Diagnóstico Meteorológico dos Desastres Naturais Ocorridos nos Últimos 20 Anos na Cidade de Duque de Caxias. Revista Brasileira de Meteorologia, v. 31, n. 3, 319-329, 2016.

MARKOV, A. A. Extension of the limit theorems of probability theory to a sum of variables connected in a chain. reimpresso no Apêndice B de: R. Howard. Dynamic Probabilistic Systems, volume 1: Markov Chains. John Wiley and Sons, 1971.

MENESES, B. M.; REIS, E.; VALE, M. J.; REIS, R. Modelling Land Use And Land Cover Changes In Portugal: A Multi-Scale and Multi-Temporal Approach. Rev. Finisterra. LIII(107), 2018, pp. 3-26.

NOVO, E. M. L. de M. Sensoriamento Remoto: Princípios e aplicações. $4^{\mathrm{a}}$ edição. São Paulo: Blucher, 2010 .

OSCAR JÚNIOR, A. C. da S. A Paisagem da Baixada Fluminense: Uma Análise na Perspectiva Geoecológica. Revista Brasileira de Geografia Física V. 06, N. 02 (2013) 195-210.

OSCAR JÚNIOR, A. C. da S. Extremos Atmosféricos e Desastres Hidrometeorológicos em Duque de Caxias (RJ). Revista Brasileira de Climatologia. ISSN: 1980-055x (Impressa) 2237-8642 (Eletrônica). Ano 11 - Vol. 17 - JUL/DEZ 2015.

OSCAR JÚNIOR, A. C. da S. Ordenamento Territorial e Riscos Ambientais de Natureza Atmosférica no Município de Duque de Caxias (RJ). Dissertação (Mestrado) - Universidade Federal do Rio de Janeiro, Instituto de Geociências, Programa de Pós-Graduação em Geografia, Rio de Janeiro, BR-RJ, 2014.

PEDROSA, B. M; CAMARA, G. "Modelagem Dinâmica e Sistemas de Informações Geográficas". In: MEIRELLES, M. S. P; CAMARA, G. ALMEIDA, C. M. de. (Org.). Geomática: Modelos e Aplicações Ambientais. Brasília: Embrapa Informação Tecnológica, 2007. p. 237-280.

PUGgian, C; RAulino, S. F. Duque de Caxias: Um Ambiente de Injustiças. Duque de Caxias: a Geografia de um espaço desigual/ André Tenreiro (organizador); Cleonice Puggian (et al.) - Nova Iguaçu, RJ: Ed Entorno, 20015.

RODRIGUEZ, D. A; LOPES, L. G; CARRIEllO, F; SIQUEIRA JÚNIOR, J. L; PINTO, G. L; TOMASElla, J; CHOU, S. C. Previsões de Cheias Extremas nos Horizontes Sazonais E de Curto e Médio Prazos na Bacia do Rio Madeira: Estudo de Caso da Enchente de 30 de Março de 2014 em Porto Velho. Revista Brasileira de Cartografia (2017), No 69/4, Edição Desastres Naturais e Impactos Ambientais: 827-836. Sociedade Brasileira de Cartografia, Geodésia, Fotogrametria e Sensoriamento Remoto, ISSN: 1808-0936.

RUHOFF, A; FANTIN-CRUZ, I; COLLISCHONN, W. Modelos de simulação dinâmica do desmatamento na Amazônia. Caminhos de Geografia - revista on line. ISSN 1678-6343. Uberlândia, v. 11, n. $36 \mathrm{dez}, 2010$. p. 258 - 268. http://www.ig.ufu.br/revista/caminhos.html

SANTOS, D. P. Meio Ambiente: Perspectivas e Desafios no Município de Franca (SP). VI Congresso Iberoamericano de Estudios Territoriales y Ambientales. ISBN: 978-85-7506-232-6. São Paulo, 2014.

SANTOS, É. P. dos; PIROLI, E. L. Detecção de mudanças no uso e cobertura da terra utilizando Land Change Modeler: o caso da bacia hidrográfica do Ribeirão do Rebojo, Pontal do Paranapanema, SP, 
Brasil. Anais XVII Simpósio Brasileiro de Sensoriamento Remoto - SBSR, João Pessoa-PB, Brasil, 25 a 29 de abril de 2015, INPE.

SILVA, A. SOUZA, E. Métodos computacionais de solução de cadeias de Markov: Aplicações a sistemas de computação e comunicação. Porto Alegre: UFRGS Inst. Informática. 1992. 195p.

SOARES-FILHO, B. S. Modelagem dinâmica de paisagem de uma região de fronteira de colonização amazônica. Tese de doutorado. - Escola Politécnica da Universidade de São Paulo. São Paulo, 1998.

SOBRAL, B. S. Variabilidade Espaço-Temporal e Interanual da Chuva no Estado do Rio de Janeiro. Revista Brasileira de Climatologia. Ano 14 - Vol. 22 - JAN/JUN 2018.

TOBLER, W. R. 1970. A computer movie simulating urban growth in the Detroit region. Economic Geography 46: 234-40.

TOMINAGA, L. K. Desastres naturais: conhecer para prevenir - Desastres Naturais: por que ocorrem? Lídia Keiko Tominaga, Jair Santoro, Rosangela do Amaral (orgs.). São Paulo: Instituto Geológico, 2009.

VISSIRINI, F; OHNUMA JUNIOR, A. A; AREAS, I; FERRELI, T. Plano Municipal de Redução de Risco de Desastres de Inundação para Duque de Caxias - Rio de Janeiro. International Conference on Urban Risks, Lisbon 30 June - 2 July, 2016.

YULIANTO, F; PRASASTI, I; PASARIBU, J. M; FITRIANA, H. L; ZYLSHAL; HARYANI, N. S; SOFAN, P. The dynamics of land use/land cover change modeling and their implication for the flood damage assessment in the Tondano watershed, North Sulawesi, Indonesia. Model. Earth Syst. Environ. (2016) 2: 47. https://doi.org/10.1007/s40808-016-0100-3. 